\title{
MULTI-SENSOR DATA ACQUISITION AND INTEGRATION PROCESSES FOR THE STUDY AND DOCUMENTATION OF THE CHURCH OF SANTA MARIA DEGLI ANGELI IN PIZZOFALCONE IN NAPLES
}

\author{
M. Pulcrano, S. Scandurra, E. Fragalà, D. Palomba*, A. di Luggo \\ DIARC, Department of Architecture, University of Naples "Federico II" \\ (margherita.pulcrano, simona.scandurra, daniela.palomba, antonella.diluggo)@unina.it, emanuela3395@gmail.com
}

KEY WORDS: Multi-sensor acquisition, Data integration, Reality-based model, Aerial photogrammetry, Point Cloud

\begin{abstract}
:
The paper presents the results of a research carried out on the Church of Santa Maria degli Angeli in Pizzofalcone in Naples, in which multi-sensor surveys have been performed in order to assess the architectonical, geometrical and colorimetric characteristics of the majestic basilica. The use of integrated technologies made it possible to realize 3D digital models that allowed the complete representation of the building, integrating data and filling the gaps of the different previous surveys. The performances of the various reality-based technologies employed have been subjected to critical analysis in order to maximize their potential, optimize survey and data elaboration phases, and obtain the expected results. These latter have been defined through the derived digital re-elaborations and representations. Hence, the objective of the research is to carry out a comparative analysis on the 3D models generated through the different active and passive sensors employed in order to proceed with their integration and achieve an accurate, original and updated methodology of building survey.
\end{abstract}

\section{INTRODUCTION}

The integration of data from multi-sensor acquisitions is a topic of great interest in the current scientific debate (Aicardi et al., 2015; Campi et al., 2018; Luhmann et al., 2019), as their potential invest both survey operations themselves, and their results. The choice to adopt a given acquisition technology and a specific data elaboration process is strongly influenced by the features of the building object of study, and by the pursued objectives, often not only aimed to the analysis of the general characteristics, but also to the evaluation and to the punctual verification of its possible critical conditions.

The experimentation, carried out on the Church of Santa Maria degli Angeli in Pizzofalcone in Naples and detailed in this article, does not only aim to the recognition and the analysis of the metric, geometric and morphological aspects of the complex, but also to produce original and update documentation and to record the state of conservation of the structures and of the rich decorative apparatus, interested by several detachment phenomena.

The paper presents a comparison between the performances of the technologies employed, concerning both laser scanning and photographic survey, highlighting the overall results of the research through the digital re-elaborations and the representations derived from it, in relation to the conducted experimentation and to the obtained documentation.

\section{CASE STUDY}

The Church of Santa Maria degli Angeli (Cautela et al., 1993; Ruotolo, 1968) rises on Pizzofalcone hill in Naples, and its eighteenth-century façade looks out on the homonymous square, now involved in the constructions works of the Neapolitan subway network.

Its construction dates back to the beginning of the $17^{\text {th }}$ century, on a design by Francesco Grimaldi, who realized a huge basilica constituted by a three-aisle plan with side chapels and a transept.
Yet, what significantly characterizes the building is the solution proposed for the majestic, monumental dome, placed on a tall tambour (Figure 1). Its configuration, together with the height of the hill, makes it visible and recognizable in the city skyline, despite being located in a dense urban texture.

In the interior part, the church is well lit and luxuriously decorated, but its vaults are affected by cracking phenomena and its stucco works suffer from detachment phenomena, which required safety works in the side aisles. In fact, in order to guarantee devotees' safety, protection nets have been realized at the height of arch imposts and aisle vaults.

The evident conditions of decay, the possibility to experiment different technologies of digital survey according to the morphological characteristics of the site, together with the purpose of realizing an in-depth analysis of the building, led the research group to design survey phases in detail. Several criticalities emerged and have been evaluated in order to direct

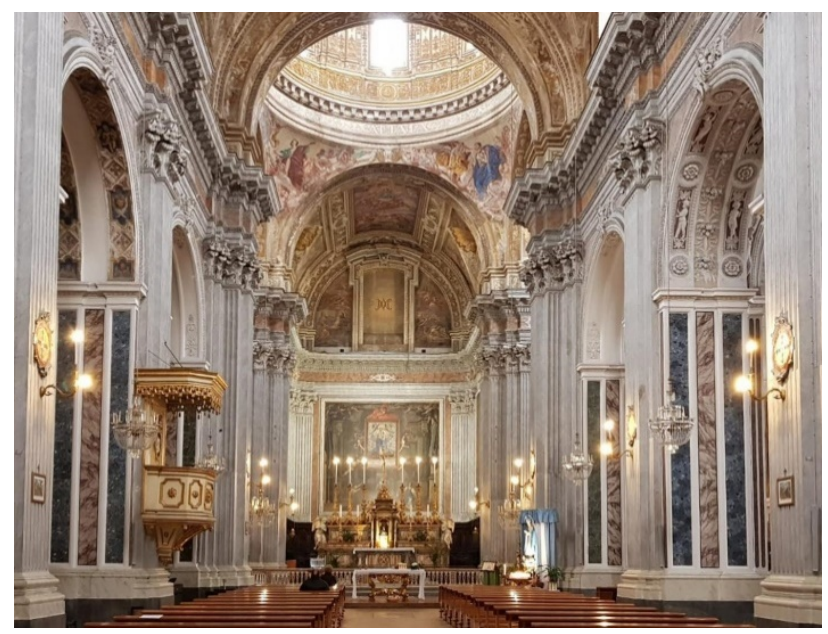

Figure 1. Interior view of the Church of Santa Maria degli Angeli

\footnotetext{
* Corresponding author
} 

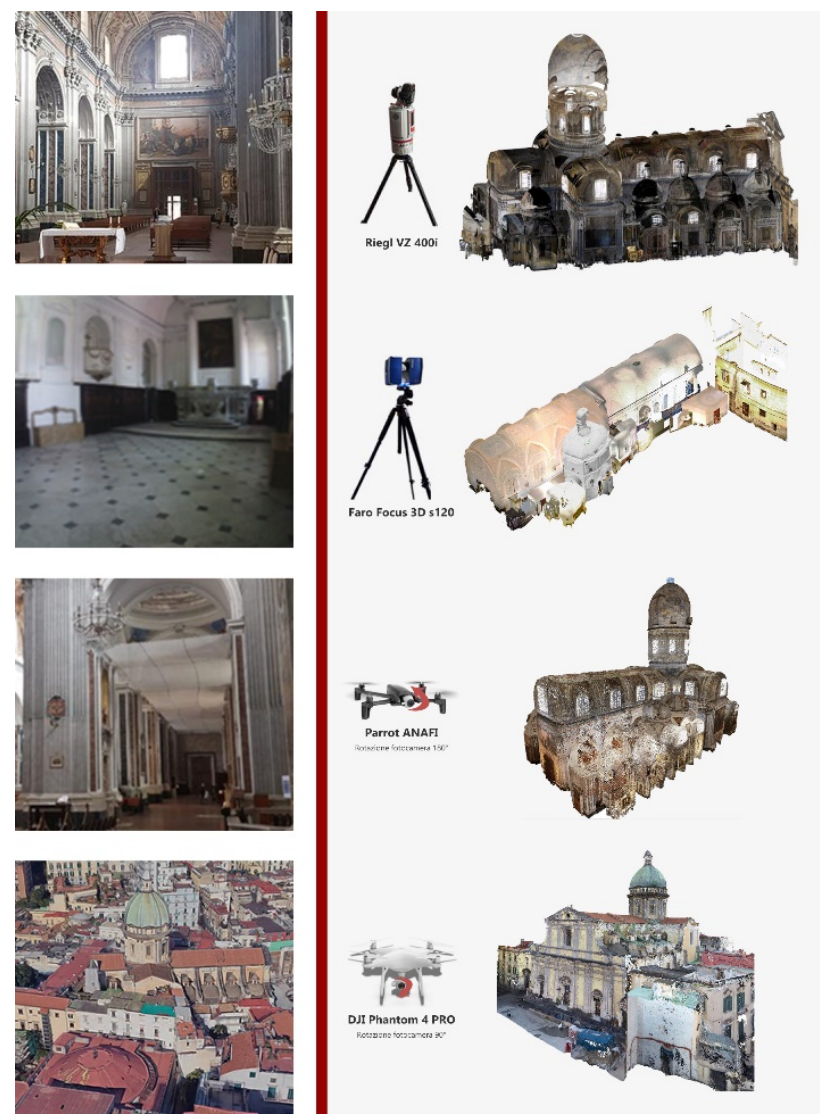

Figure 2. Overview of the morphological characteristics of the site, of the reality-based technologies used and of the 3D models obtained

data acquisition campaigns correctly, and to obtain a complete and accurate representation of the building, both in its internal and external components

Concerning the survey of external parts, for example, it has been necessary to take into account the impossibility to access southeast and southwest facades by walking, because of the dense building texture around them, but also because of the adjacent presence of the Military Courthouse and the Military Prosecution of the Republic. In particular, these latter have raised the issue of identifying procedures in compliance with the military sites during the programming phase of survey activities. Moreover, the presence of the construction site of the subway station, which almost totally covers the square in front of the church, has influenced the choice of the tool to employ, considering the limited area for its deployment.

Concerning the interior part, on the other hand, it has been necessary to deal with the huge building scale of the basilica. However, the main criticality is represented by the presence of safety nets that totally hide the vaults of the two side aisles. So, the necessity to survey these parts has encouraged experimentations based on the integrated use of reality-based survey technologies and methods.

\section{SURVEY DATA ACQUISITION AND ELABORATION}

The need to organize a complete survey of the majestic building, with in-depth details of the stucco works, partially hidden by the safety nets, has required a careful consideration of the acquisition processes and of the technologies to employ during the whole survey campaign. In fact, it has been essential to individuate the suitable tools to overcome the criticalities of the specific site, in order to survey accurately both the exterior and the interior, and to obtain a valid result to represent the site condition.

After evaluating the numerous complexities found, data collection was divided into different phases, where different reality-based survey technologies have been used (Figure 2), in some cases in unconventional modalities. Likewise, point cloud processing and editing has been differentiated according to the type of surveyed data - directly in the form of 3D model when obtained through range-based sensors, and as a photographic dataset for the image-based ones - to the software used and to the reiterated computational process.

\subsection{Range-based surveys with Time of Flight (ToF) sensor}

The first survey campaign has involved the church interior, in relation to the spatial definition of the structures that constitute the central aisle, the side aisles, the chapels, the transept and the choir; the accessible exterior facades were considered together with these as well. The reflections on the site condition and, in particular, on the occlusion in the top part of the side aisles drove the choice of the tool to employ and led to the individuation of Riegl VZ400i time-of-flight laser sensor as the most suitable technology to limit information loss. The main factors behind this choice are represented by its sensor technology and its use in association with RiscanPRO software, which allows semiautomated 3D model filtering in relation to set values of reflectance and points classification (echo).

The intrinsic characteristics of laser and, specifically, a limited acquisition range on the vertical axis (100-degree angle of view) required an accurate campaign phase planning, through the preventive individuation of stationing points of the tool, in order to determine all the necessary scans to cover all the areas and obtain complete and homogeneous data. Moreover, the operation of varying the angle of the tool by rotating it on the vertical axis and placing it on specific supports, turned out to be a useful device to remedy shadow areas and complete the metric, geometric and colorimetric data of the vaults placed upon the presbytery and the side aisles.

So, during data acquisition, the scanning route (Figure 3) was divided into two parts, proceeding with closed polygonal lines converging toward the central aisle from the side aisles. On one hand, the choice to follow this approach results in unnecessary scan positions, as they take include areas that have already been
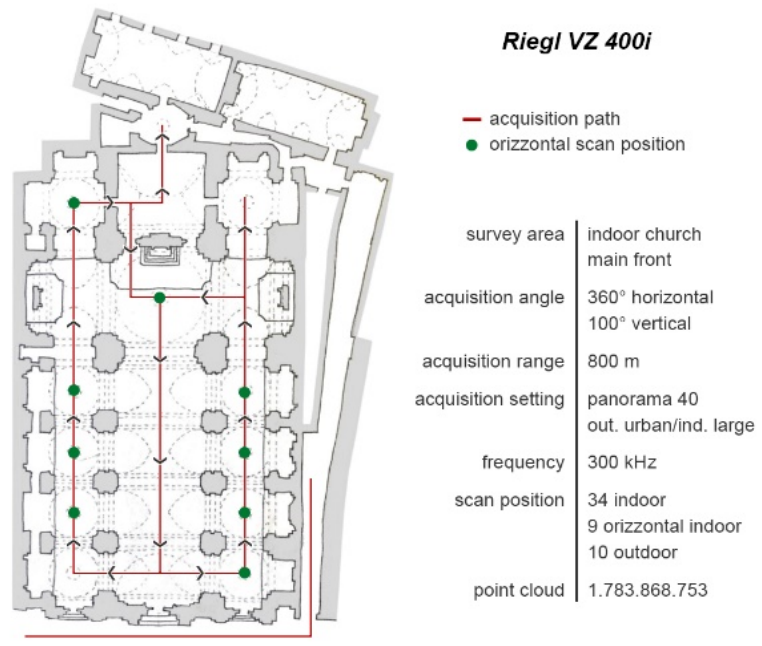

Figure 3. Range-based survey with TOF: route scheme and characteristics of the instrument 


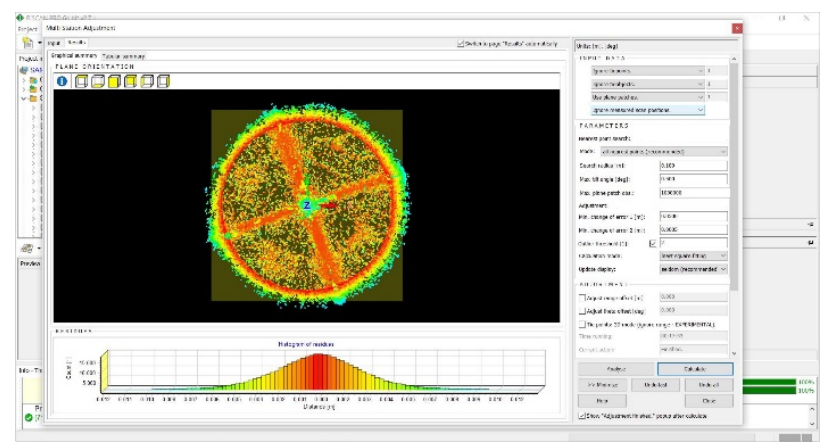

Figure 4. Check of the automated alignment of scan positions: results of the multi station adjustment process

surveyed; on the other hand, it is necessary to ease the instrument in chaining them. In fact, it is necessary to highlight that Riegl VZ400i performs a preliminary alignment of point clouds contextually to data acquisition, relating them on the basis of natural reference points and plans found on the site. Closing the line, then, makes it possible to perform automatic corrections and increase the data accuracy in terms of overlapping between areas and homologue elements, therefore improving the quality of the final point cloud. Of course, this automated process does not produce the expected results for the acquisition that employed the rotation of the system. In those cases, in fact, it was necessary to adopt manual alignments, individuating in RiscanPRO pairs of homologous points, used as references to align them to the rest of the survey by rototranslation. In order to validate the procedure, tests were performed through automatic registration and multi station adjustment, providing very slight error values (around $6 \mathrm{~mm}$ ) which confirmed the final model (Figure 4). Finally, some annexes to this route allowed surveying the octagon-shaped section placed behind the choir and the end of the right aisle. While an additional polygonal line, in this case open and formed only by two arms, produced the 3D model of the main façade, and part of the northwest one. So, in total, 52 scan positions have been used, of which 43 for the interior - in particular, 10 by rotating the tool in the horizontal axis - and 9 for the exterior of the church.

The tool was calibrated by relating its default settings to the geometric and material characteristics of the site: panorama 40 mode was chosen, with an outdoor urban/indoor large scenery type and a $300 \mathrm{kHz}$ frame rate.

During data processing, performed through RiscanPRO and automated phases, the various points constituting the 3D model were subdivided into layers according to their echo (Di Salvo and Lo Brutto, 2014; Pirotti et al., 2013), which represents the way the laser ray surveyed the surfaces, if directly or passing through obstacles (Figure 5; Figure 6). Additional differentiations were applied by defining a range in the reading of reflectance values for each point. This allowed to ease and speed up point cloud
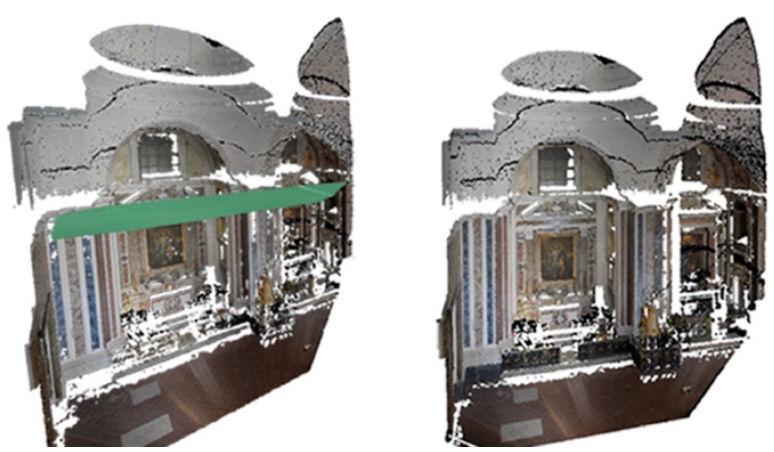

Figure 5. Automated filtering by selecting echo: pre and postcleaning point cloud

editing and noise removal, reverberation filtering and the exclusion of all the other elements considered not to be significant in the representation of the building object of study. In fact, the operation was fundamental to produce a virtual removal of the safety nets from the point cloud, and to realize an overall unitary view of the structures that constitute the interior of the church.

\subsection{Range-based surveys with phase modulation sensor}

In order to obtain a model as complete as possible, a second survey campaign involved the acquisition of the part of the northwest façade that was not reached by Riegl VZ400, and of the sections that could be accessed from the choir such as the Sacristy, the private Chapel and some ancillary rooms. The evaluations concerning the dimensional characteristics of these spaces - notably smaller than the main room of the Basilica - led to the adoption of a different equipment, even though belonging to the range-based technologies. In this case, in fact, it was chosen to use phase modulation laser sensor FaroFOCUS 3D s120, whose characteristics made more suitable for the typology of survey.

2D and 3D targets, spherical and grid plans were used as references for the alignment between the scan positions. Therefore, in addition to the route design and to the individuation of acquisition parameters, a particular attention was given to their collocation so that they could be visible from different stationing points.

For this second survey, 11 scans - with a resolution between 7 and $12 \mathrm{~mm}$ on the reference distance of $10 \mathrm{~m}$, with triple point detection and contextual acquisition of photographic frames in order to associate points also with colorimetric information were performed. The overall point cloud creation was realized through the FaroSCENE proprietary software. After verifying the exact automated individuation of the targets, the alignment process that has generated the final 3D model was started.
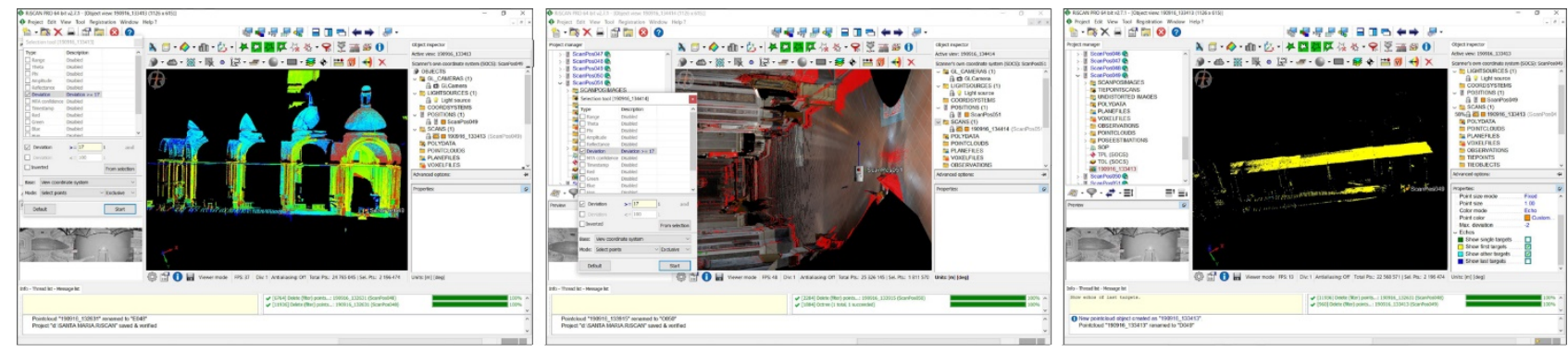

Figure 6. Automated filtering of the point cloud in the RiscanPRO software based on reflectance values and echo 

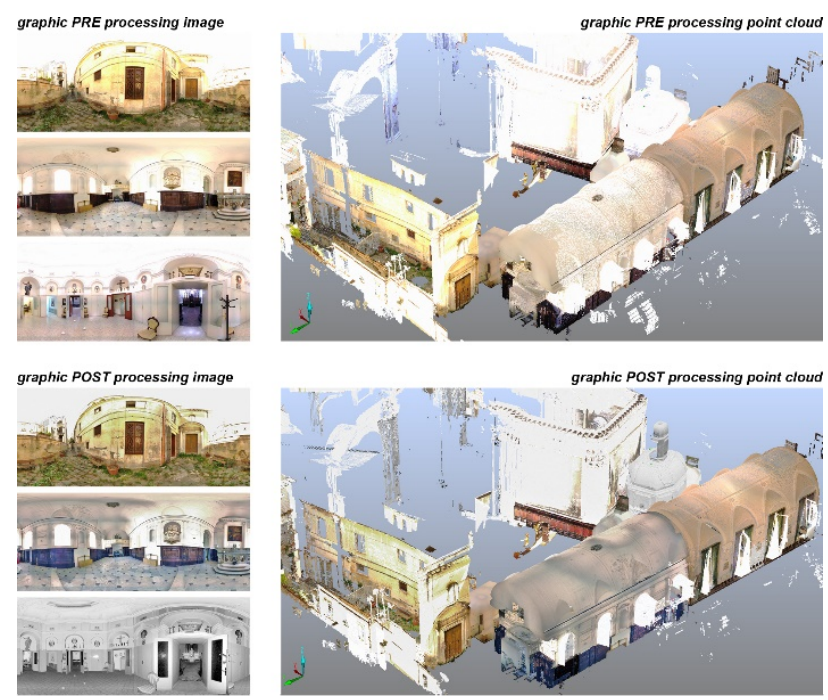

Figure 7. Editing of the point cloud acquired by the FaroFOCUS 3D s120 laser: results before and after graphic correction with the application of color contrast and white balance filters

The lighting conditions of the site, in some cases excessive, have produced a partially overexposed point cloud, where the represented elements were difficult to read due to their excessive brightness. This factor required the application of some photo editing corrections in order to improve the graphic-visual quality of the model. Specifically, color contrast filtering and white balancing processes were used, and their settings allowed improving the coloring of the point cloud (Figure 7).

\subsection{Remotely Piloted Aircraft System (RPAS) for the survey of the interiors}

Though range-based surveys were performed analyzing critically the potential of the employed tools and hypothesizing the possible results, of course for some of the elements and/or parts of the structure the point cloud presents a lack of information. So, in order to complete the data, the areas at taller heights which were not detected by range-based tools were chosen to be subjected to further image-based surveys. Specifically, the laser point cloud was integrated with aerial photogrammetric acquisitions, especially for the definitions of the vaults inside the church, both those covered by safety nets and those that were not. Parrot ANAFI was used for this purpose, considered to be particularly suitable thanks to its possibility of orienting the camera in a $180^{\circ}$ range, and to its small dimensions. Of course, the flight of the drone was controlled in manual mode, driving the vehicle above the obstructing elements, and paying attention to ensure the correct overlapping between the single photograms acquired, in order to prevent the results from being invalidated during photogrammetric processing. In this way, it was possible to represent in detail the internal side of the various domes and vaults, in addition to the roof lanterns placed on their top. For these latter, in particular, the route of the drone was driven vertically, and through 360 degrees on the horizontal axis. That is, choosing an approximately central position, shots were taken at slightly different heights by rotating the drone on itself in order to survey the whole cylindrical surface that characterizes the element.

This first image-based survey provided a high number of photographs (around 5.000 frames), necessary to report accurately the site condition (Figure 8).

Processing photographic images required the application of the traditional photogrammetric pipeline, yet subdivided in different phases in order to manage adequately the high quantity of acquired information. The first general point cloud, in fact, was obtained from medium resolution processing, and became the base for the following ones. These latter, in particular, involved the implementation of data through higher resolution settings, and the definition of more limited areas for the computation. In this way, a higher accuracy was achieved both in geometry and in photo-realistic rendering, limiting the use of hardware resources and optimizing processing times. As a consequence, the first model provides general and overall information on the Church, while the following ones allow more in-depth studies on its structures, through the recognition of details which would not be individuated otherwise, and on its state of conservation (Figure 9).

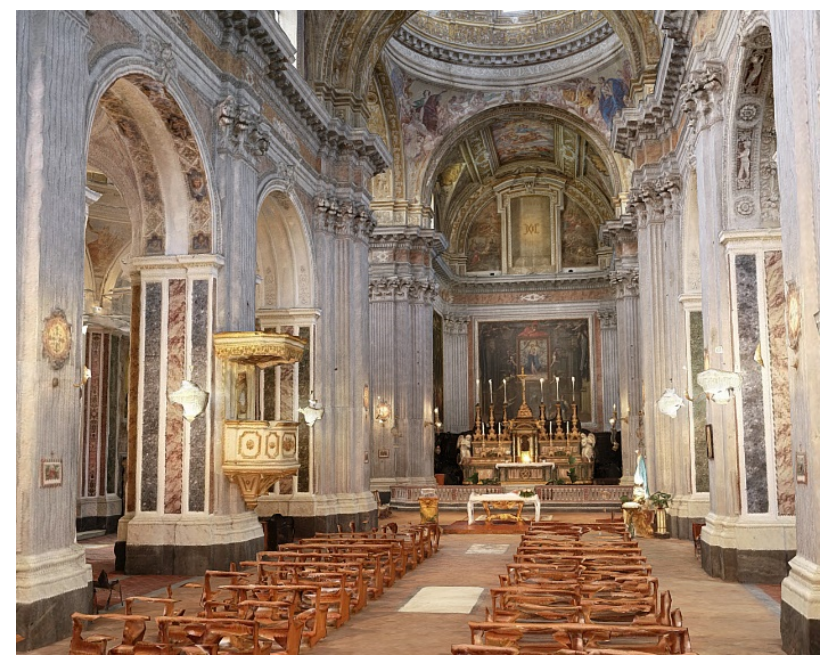

Figure 8. Texturized polygonal model: view of the apse area from the central aisle
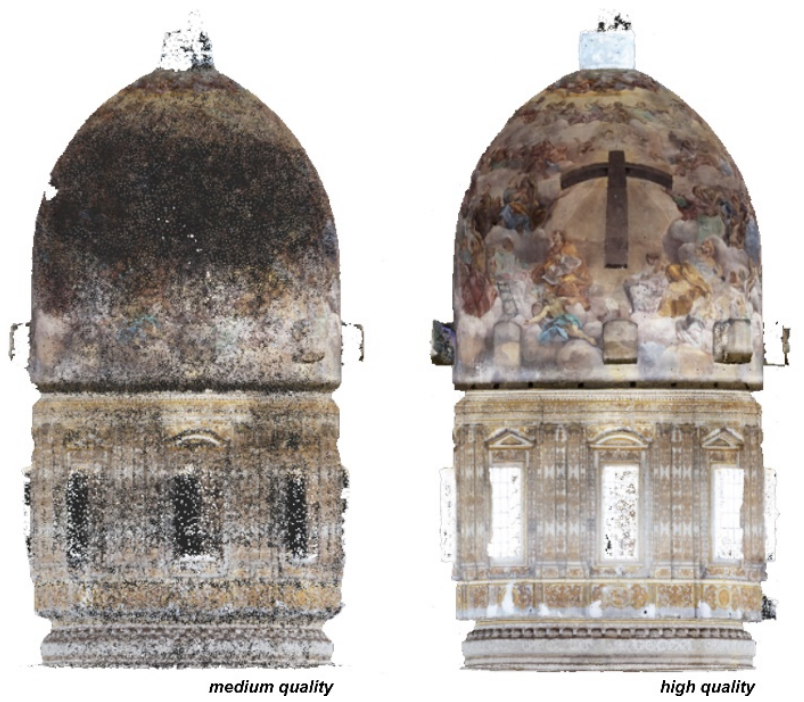

Figure 9. Image-based point cloud processed by the Parrot ANAFI dataset: detail of the dome obtained by the process in medium and high quality 

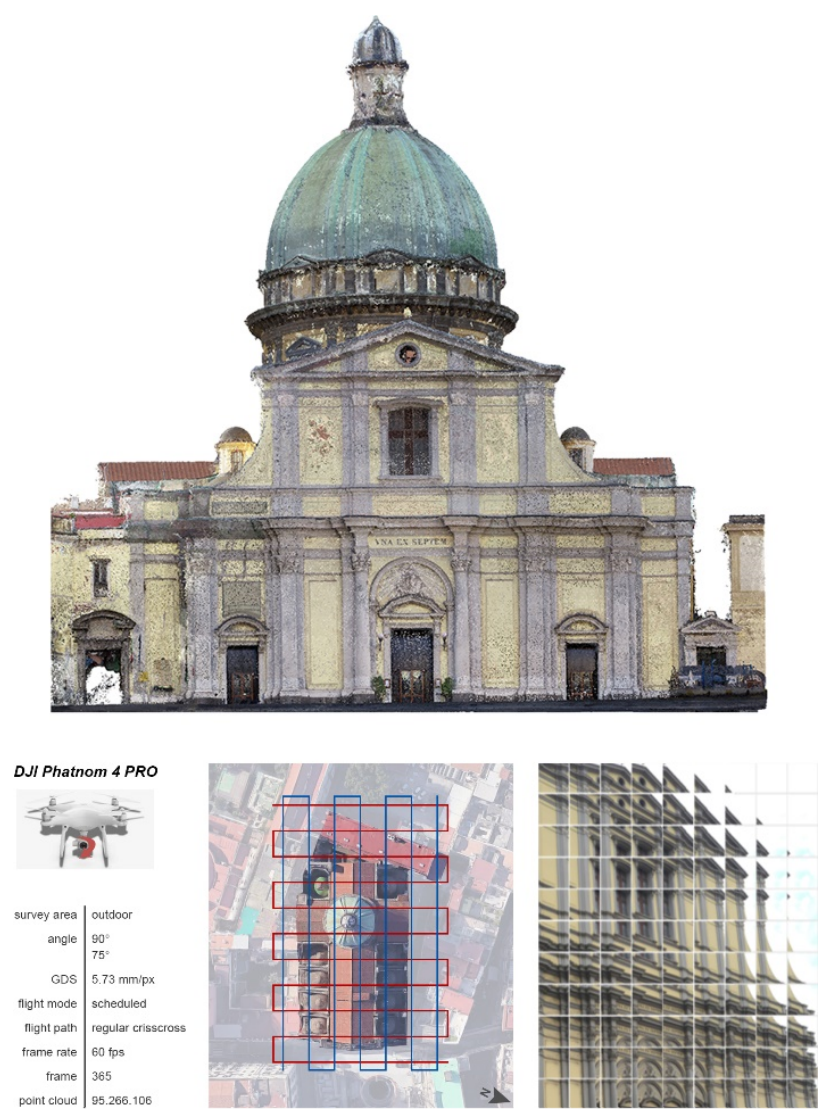

Figure 10. External image-based survey: settings and acquisition route, photographic dataset and processing results in SfM software

\subsection{Remotely Piloted Aircraft System (RPAS) for the survey of the exterior}

The last survey campaign (Figure 10) made it possible to acquire morphometric data from the exterior of the basilica and the adjacent urban texture. In this case, a DJI Phantom 4 PRO with programmed flight was used, integrating nadiral and angled acquisitions in order to obtain complete information on roofs, wall structures and façades. For these latter, in particular, the use of aerial photogrammetry allowed to obtain data that could not have been collected otherwise, especially for carved parts (southeast and southwest façades).

The surveyed area was subdivided according to a regular crossed grid, that includes the whole complex of the church in its longitudinal and cross-section dimensions. The acquisitions have a $5.73 \mathrm{~mm} / \mathrm{px}$ GDS and the resulting photographic dataset composed by 365 photograms.

Together with the image-based survey realized with Parrot ANAFI, the processing followed the various operational phase that led from the coarse point cloud, constituted by the homologous points individuated in the various frames, first to its densification and then to the construction of the texturized polygonal model. Yet, differently from the previous case, everything was managed through a single computational process. Finally, both image-based models were proportioned to the correct real dimension by relating reference points and measurements to the corresponding virtual elements in the digital environment.

\section{COMPARISON AND INTEGRATION OF REALITY- BASED SURVEY DATA}

The quantity of data obtained from reality-based surveys constitutes a fundamental support to the analysis of the complex, in its ensemble and details. Yet, the fragmentary nature of information, due to the combined use of different tools, required a mutual integration in order to proceed to a unitary and complete reading of the structures and the elements that constitute the Church of Santa Maria degli Angeli.

Preliminary for this phase of the research were comparisons between the point clouds. This operational choice was motivated by the purpose of verifying the presence of differences between the models in order to obtain consistent data following integrations. The selection of the methodology was driven by reflections regarding their own characteristics - in terms of file size and morpho-geometrical complexities of the site - and the presence of common areas. This latter aspect, in particular, has been decisive in the evaluation of obtainable results, as proceeding with $3 \mathrm{D}$ cloud-to-cloud comparisons data which

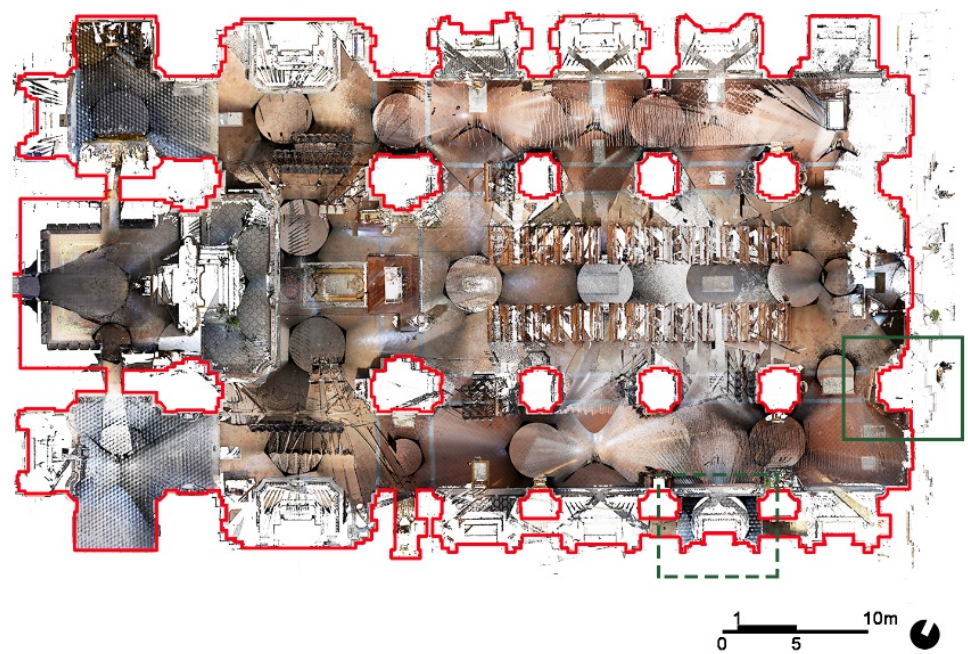

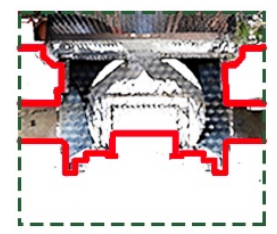

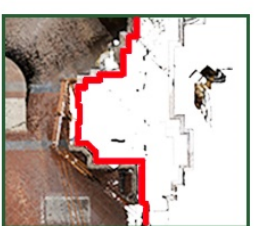

- Riegl VZ 400i

- Parrot ANAFI
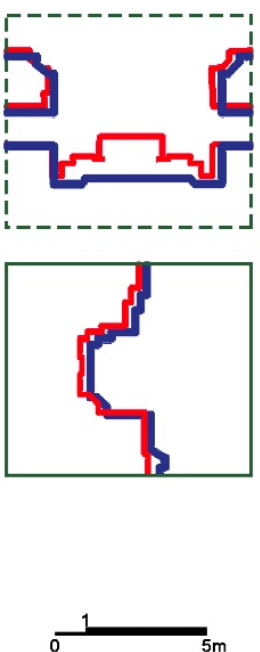

Figure 11. 2D comparisons between the profiles extracted from the range-based (Riegl VZ 400i) and the image-based point cloud (Parrot ANAFI dataset) 

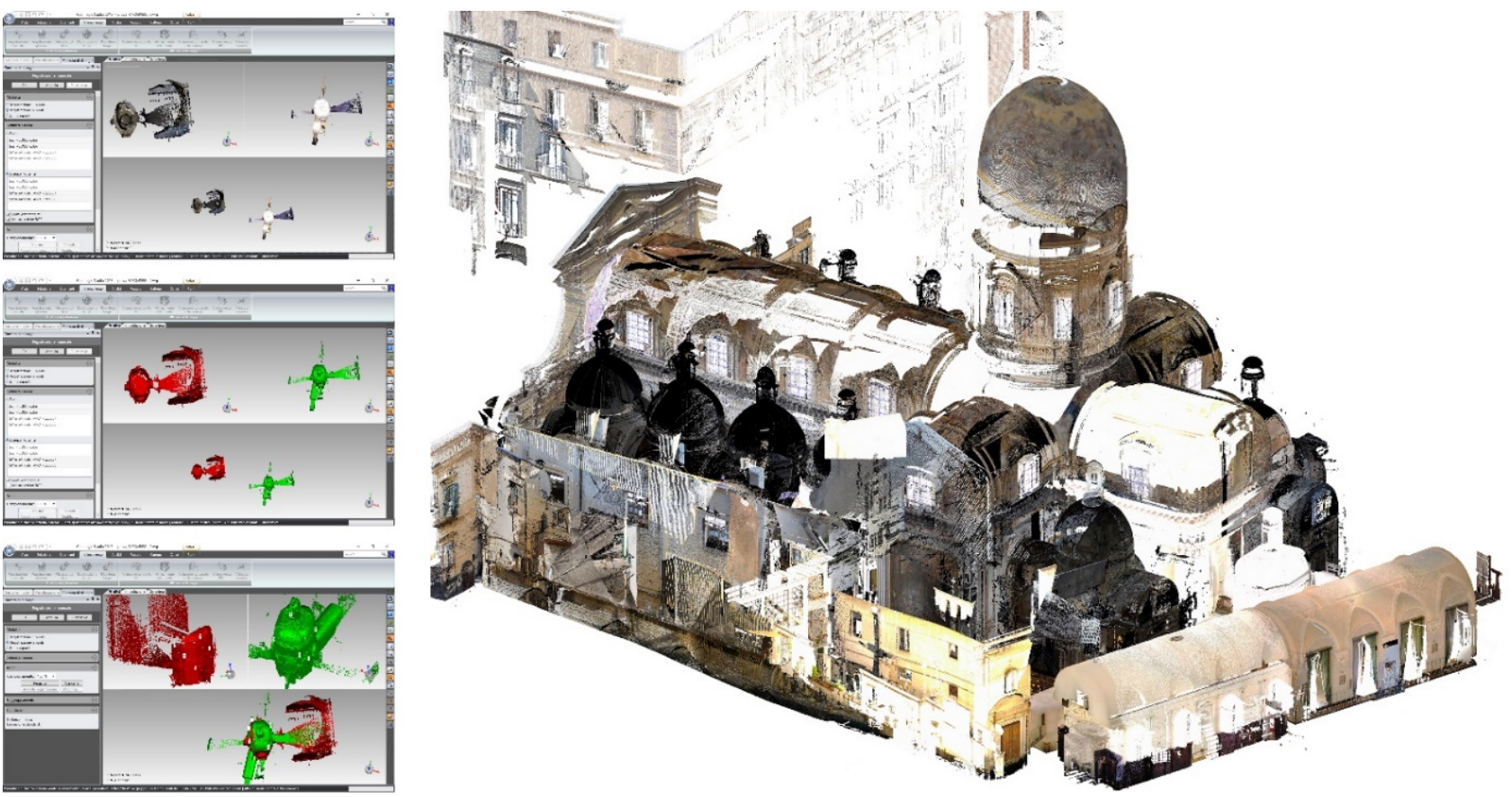

Figure 12. Integration of range-based models into the Geomagic Studio software

could not be sufficiently overlapped would have determined an incorrect estimation of the analysis, with range of values referred to the 3D model, and not only to the common parts. Then, 2D comparisons were performed (Landes et al., 2007; Pulcrano et al., 2019) to evaluate the correspondence of the total dimension of the church by extrapolating ortophotographic plans of the floor plan (at different heights) and prospects (both in longitudinal and cross-section direction).

The point cloud acquired by Riegl VZ400i was individuated as the reference parameter and the initial evaluation considered the photogrammetric model obtained from the surveys of Parrot ANAFI. So, after extracting the views to be used in the comparison, their overlapping in a CAD environment highlighted the great degree of concordance between the two models except for a few elements, such as the bottom wall of some chapels and the internal profile of the main façade, which show a negligible deviation, within few centimeters (mean value around $2.73 \mathrm{~cm}$ ) (Figure 11). It has to be pointed out that, especially in reference to the side chapels, the data from Riegl VZ400i result to be incomplete as the acquisition process did not regard their internal part because of the well-known problems in operating in limited spaces with tools like this, where the presence of fixed furnishings represent a further limitation to data registration. As a consequence, the observed dimensional difference, which can be attributed to the lack of information in range-based point cloud, did not affect the positive evaluation of the image-based model.

The same procedure was followed also for the secondo photogrammetric point cloud. In this case, the object of comparison was the main façade of the church, being the only element in common between reality-based surveys. As in the previous analysis, no notable variations of the morpho-geometric data were detected and various shadow areas in the data from Riegl VZ 400i, places in the top part of the façade and in correspondence of the overhangs, depend both on the position of the tool during campaign phase, and on it acquisition field. Finally, after validating the results of photographic dataset processing, the integration of reality-based data appeared to be a fundamental choice to fill the gaps of the models and complete the metric and geometric information of the church.

\subsection{Point cloud integration}

When performing the integration of reality-based models, it was chosen to keep the spatial structure of the single point clouds unaltered and to adopt an approach consisting only in the registration in one common reference system. Actually, only apparent unions were reached, with data overlapping rather than fusion, but this nevertheless allowed to obtain a complete final model and to individuate the contribution of each single survey. The choice to proceed according to this integration methodology was driven by the need to make the data manageable during the following phases of analysis of the conservation state of the church, both in relation to the reading of the different parts that constitute it and to their viewing and editing.

The application chosen to carry out this part of the experimentation was Gemagic Studio and, operatively, the integration process started with the conversion of the data in compatible formats .ptx and .xyz. This allowed a correct reading of the models, limiting the possible data loss (regarding geometry, position, color, etc.). Before that, data were exported from the proprietary software associated with range-based tools ad from SfM elaboration software in order to proceed to import point clouds in the same digital environment and with their registration in the same model space.

The union of these data was performed by replicating the framework for the raw alignment of 3D models that, as it is wellknown, includes setting references first, that is setting objects from which information on position, orientation and dimensions can be obtained, and then the manual individuation of point and homologous elements as a reference for the second model, which is subjected to rototranslation - and, if necessary, scaling (Huang et al., 2017). After deciding the point cloud to be considered locked in its reference, the others were aligned following the same procedure but choosing, from time to time, the most suitable correspondences to perform the process. 


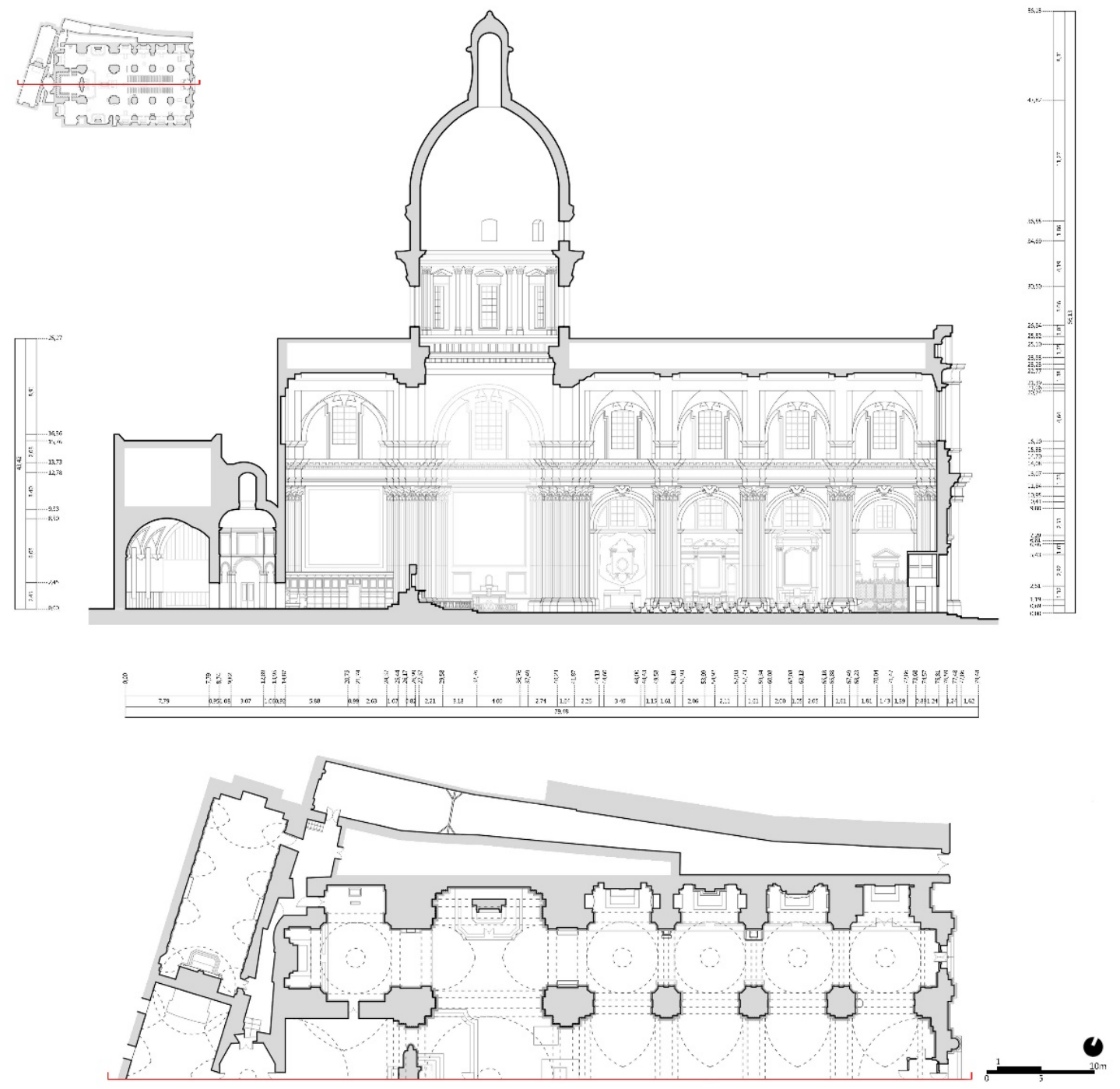

Figure 13. Graphic elaborations of the Church of Santa Maria degli Angeli based on the point cloud

Similarly to the procedure followed in the comparisons, also integrations were carried out based on the results obtained from the survey with Riegl VZ400i, that is in relation to the common parts that allowed a correct overlapping of the others.

Specifically, the first aligned point cloud was the range-based one acquired through FaroFOCUS 3D s120 (Figure 12). The survey of the choir and of the octagonal-shaped section behind it, realized by both tools, was designed just for this specific research phase. So, various points were individuated through the tools provided by Geomagic Studio, and even though their choice depends on the operator, the registration is performed through automated computations. After that, the software returns mean and standard deviation values, obtained as the difference between the coordinates of reference points. The results of this first point-to-point process show very small error values (within few millimeters), making it possible to validate them without applying corrections.

3D models obtained from photographic datasets were aligned by individuating correspondences on the main external façade - for the point cloud obtained from the frames of DJI Phantom 4 PRO - and in the central aisle - for the one from Parrot ANAFI. This latter, in particular, considering the wide area of overlap with the range-based survey, was also object of refined alignment processes - through global registration - that allowed to improve the final result.

\section{CONCLUSIONS AND FUTURE DEVELOPMENTS OF THE RESEARCH}

The research carried out is part of the wider context of the digitalization of Cultural Heritage, where - despite making use of consolidated techniques and technologies - new challenges and points for discussion appear regarding the use of procedures, the integration of obtained results and their employment for a complete and detailed study of the surveyed building.

In this research, the necessity to report adequately the shapes and the elements that constitute the church, overcoming on-site physical obstacles, has led the work team to cogitate and individuate the methodologies and the tools that suited best the pursuit of the fixed objectives. These are related to the determination of an accurate reference system to be used as a support for the following analyses on the evaluation of the conservation state of wall, vaulted and decorative structures. The 3D digital surveys realized allow, in fact, to analyze the complex and articulated building a different detail scales, not just reporting its configurational aspects but also serving as a source of 

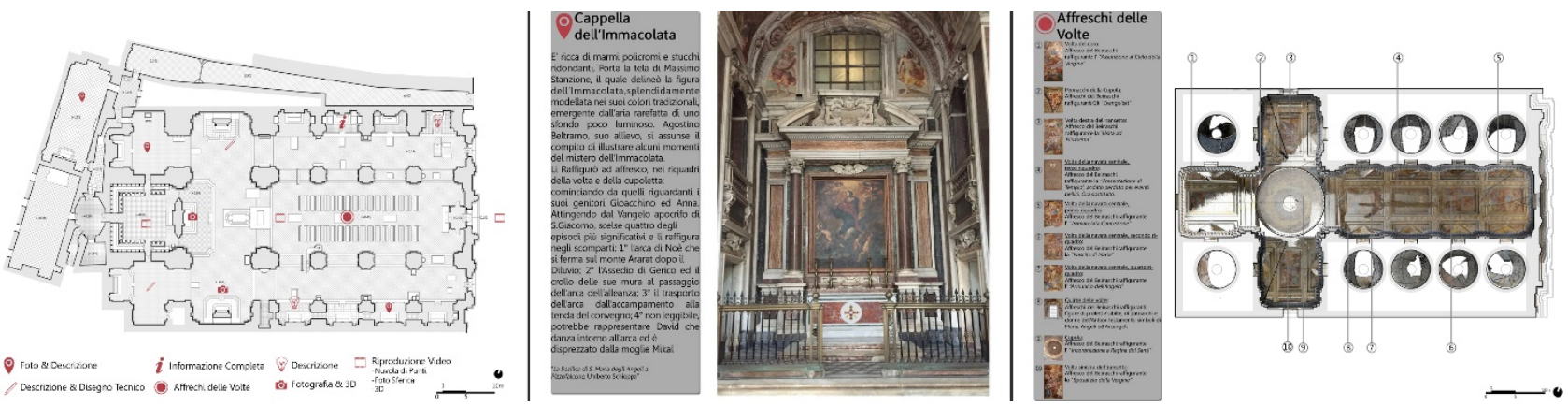

Figure 14. Virtual Tour of the Church of Santa Maria degli Angeli: detection of points of interest and visualization of the associated information content

knowledge and monitoring about decay and detachment phenomena. For this purpose, starting from the high quantity of acquired data, orthographic representations have been realized in a CAD environment (Figure 13), as a graphical synthesis for the mapping of these phenomena.

Also, these studies may give start to a project of valorization and promotion of a particularly significant architecture in the city of Naples, in addition to support interventions aimed to remedy the poor conditions of conservation of the complex. The present study has also experimented modalities of virtual fruition of informative and descriptive contents of the basilica (Figure 14). This experience follows the consolidated example of interventions that propose projects of fruition and valorization of museums, cultural venues, and places of cultural and historical interest through the realization of virtual tours where it is possible to access information associated to POI, points of interest. These are examples that can be employed in valorization projects aimed to offer virtual experiences that could enrich and improve the experience of visiting a site of historical, artistic and architectonical interest. Specifically, it is in fact possible to access virtual fruitions of the vaults and the decorative apparatus, currently hidden by safety nets. This experience, designed to compensate a temporary condition, can also be implemented with other contents. The basilica is characterized by a rich decorative apparatus constituted by stucco works and murals, most of which located at heights, so it is not possible to see all of them. The possibility to offer detailed and close-up views of them is provided by the high-resolution photographic pictures and recordings realized through Parrot ANAFI.

Finally, it is emphasized that the choices made, coherently with the present proposals of the scientific scene, have been performed relating acquisition processes to obtainable results. These latter highlight how reality-based applications served by no-contact sensors, despite being assimilable to each other in their formal and conceptual structure, show in reality unique characteristics influenced by the specific conditions of the operating environment.

\section{REFERENCES}

Aicardi, I., Boccardo, P., Chiabrando, F., Donadio, E., Lingua, A., Maschio, P., Noardo, F., and Spanò, A., 2015. Modelli 3D multisensore per l'acropoli segusina. SEGUSIUM, Arco di Augusto - Susa - Anno LII, pp. 195-216.

Campi, M., di Luggo, A., Monaco, S., Siconolfi, M., and Palomba, D., 2018. Indoor and outdoor mobile mapping system for architectural surveys. The International Archives of the Photogrammetry, Remote Sensing and Spatial Information
Sciences, vol. XLII-2, pp. 201-208. https://doi.org/10.5194/isprsarchives-XLII-2-201-2018

Cautela, G., Di Mauro, L., Spinosa, N., and Ruotolo, R., 1993. Napoli sacra: guida alle chiese della città di Napoli. Elio de Rosa.

Di Salvo, F., and Lo Brutto, M., 2014. Full-Waveform Terrestrial Laser Scanning for Extracting a High-Resolution 3D Topographic Model: a Case Study on an Area of Archaeological Significance. European Journal of Remote Sensing, vol. 47, pp. 307-327. https://doi.org/10.5721/EuJRS20144719

Huang, J., Wang, Z., Gao, J., Huang, Y., and Towers, D. P., 2017. High-Precision registration of Point Clouds Based on Sphere Feature Constraints. Sensors, vol. 17, n. 72. https://doi.org/10.3390/s17010072

Landes, T., Grussenmeyer, P., Voegtle, V., and Ringle, K., 2007. Combination of terrestrial recording techniques for 3D object modelling regarding topographic constraints. Example of the Castle of Haut-Andlau, Alsace, France. XXI International CIPA Symposium, pp. 435-440.

Luhmann, T., Chizhova, M., Gorkovchuk, D., Hastedt, H., Chachava, N., and Lekveishvili, N., 2019. Combination of terrestrial laser scanning, UAV and close-range photogrammetry for $3 \mathrm{~d}$ reconstruction of complex Churches in Georgia. Int. Arch. Photogramm. Remote Sens. Spatial Inf. Sci., XLII-2/W11: 753761. https://doi.org/10.5194/isprs-archives-XLII-2-W11-7532019

Pirotti, F., Guarnier, A., and Vettore A., 2013. Vegetation filtering of waveform terrestrial laser scanner data for DTM production. Applied Geomatics, vol. 5, pp. 311-322. https://doi.org/10.1007/s12518-013-0119-3

Pulcrano, M., Simona, S., Minin, G., and di Luggo, A., 2019. 3D Cameras acquisitions for the documentation of Cultural Heritage. The International Archives of the Photogrammetry, Remote Sensing and Spatial Information Sciences, vol. XLII-2/W9, pp. 639-646. https://doi.org/10.5194/isprs-archives-XLII-2-W9639-2019

Ruotolo R., 1968. Documenti sulla chiesa di S. Maria degli Angeli a Pizzofalcone. Napoli Nobilissima, vol. VII, pp. 219225. 